\title{
As doenças e agravos não transmissíveis, o desafio contemporâneo na Saúde Pública
}

Este número dedicado às "Doenças e Agravos Não Transmissíveis (DANT)" torna-se fundamental dado o desafio contemporâneo no enfrentamento destes agravos que combinam dois grupos de eventos: as doenças crônicas não transmissíveis - DCNT (como as cardiovasculares, neoplasias, respiratórias crônicas e diabetes) e as causas externas (acidentes e violências). As DANT representam a maioria das causas de morbimortalidade no mundo e no Brasil, além de resultarem em mortes prematuras, incapacidades, perda da qualidade de vida e importantes impactos econômicos.

O aumento da carga de DCNT afeta mais as pessoas de baixa renda e reflete os efeitos negativos da globalização, das desigualdades no acesso aos serviços de saúde, da urbanização rápida, da vida sedentária e da alimentação com alto teor calórico e do marketing que estimula o uso do tabaco e do álcool. No caso das violências existem sólidas evidências que destacam as desigualdades associadas aos recortes de gênero, raça/cor, baixa escolaridade e renda, pessoas com deficiência, crianças e idosos, dentre outros, populações estas que devem ser priorizadas em políticas públicas de promoção da equidade.

Nos Objetivos do Desenvolvimento Sustentável e na agenda 2030, diversos indicadores referentes às DANT foram incluídos, como metas de redução da mortalidade de DCNT e das mortes no trânsito, metas de redução do tabaco e do consumo abusivo do álcool, eliminação da violência contra mulheres e meninas, acesso a sistemas de transporte seguros, sustentáveis, expansão do transporte público. Estas metas reforçam a ação intersetorial.

O Brasil possui importantes marcos no seu compromisso com o tema, como a criação da Coordenação Geral de DANT em 2003 no Ministério da Saúde, a organização da Vigilância de DANT, para o monitoramento destes agravos. Destaca-se ainda a criação do sistema de inquéritos nacionais, contendo as pesquisas domiciliares a cada cinco anos, como a Pesquisa Nacional de Saúde em 2013, os inquéritos telefônicos, Vigitel, com início em 2006 e já com onze anos de coleta contínua, a Pesquisa Nacional de Saúde do Escolar (PeNSE) a cada três anos (2009, 2012, 2015), a Vigilância de Violências e Acidentes (VIVA), em seus dois componentes, inquéritos trianuais, e a notificação compulsória das violências domésticas, além da articulação com os Sistemas de Informação de Mortalidade (SIM) e hospitalar (SIH). A vigilância de DANT constitui um marco na saúde pública brasileira inovando no apoio às políticas públicas de prevenção e controle.

Outras agendas fundamentais em DANT foram a) aprovação da Política Nacional de Promoção à Saúde (PNPS) em 2006, sua revisão em 2014, reiterando o compromisso com a equidade, a melhoria das condições e dos modos de viver e a afirmação do direito à vida e à saúde'; b) O Plano de Enfrentamento de DCNT 2011-2022 que estabeleceu metas para a redução de fatores de risco e das DCNT e definiu um conjunto de ações no campo da promoção da Saúde, prevenção, vigilância e assistência. c) As ações e as políticas regulatórias custo-efetivas como o aumento de impostos e do preço do tabaco, criação de ambientes livres de tabaco, advertências sanitárias, com destaque ao Decreto Presidencial de Ambientes livres de Tabaco em 2014. A Lei Seca em 2008 e o seu aperfeiçoamento em 2012, proibindo beber e dirigir. d) O Projeto Vida no Trânsito, atuando de forma intersetorial e reduzindo mortes no trânsito.e) O Guia de Alimentação saudável em 2014, reiterando a mensagem da alimentação saudável na melhoria da qualidade de vida.

O aprendizado em relação as DANT é organizar a vigilância destes eventos, atuar na redução das desigualdade e iniquidades, instituir agenda regulatória que reduza vulnerabilidades, e sobretudo atuar de forma participativa, articulada e intersetorial.

Deborah Carvalho Malta ${ }^{1}$; Marta Maria Alves da Silva ${ }^{2}$

${ }^{1}$ Escola de Enfermagem, Universidade Federal de Minas Gerais

${ }^{2}$ Universidade Federal de Goiás

Referências

1. Malta DC, Morais Neto OL, Silva MMA, Rocha D, Castro AM, Reis AAC, Akerman M. Política Nacional de Promoção da Saúde (PNPS): capítulos de uma caminhada ainda em construção. Cien Saude Colet 2016; 21(6):1683-1694. 